\title{
TATTOO MEANING RECONSTRUCTION IN TATTOO COMMUNITY MEMBERS
}

\author{
Amir Dedoe
}

\author{
Faculty of Social and Political Sciences, Universitas Bangka Belitung
}

Corresponding Author: Amir Dedoe, E-mail: amirdedoe1963@gmail.com

\begin{tabular}{l}
\hline ARTICLE INFO \\
\hline Received: $2020-09-24$ \\
Accepted: 2021-03-30 \\
Published: 2021-03-31 \\
Volume: 4 \\
Issue: 1 \\
DOI: \\
https://doi.org/10.33019/berumpun.v3i2.41 \\
\hline KEYWORDS \\
\hline
\end{tabular}

\section{ABSTRACT}

Tattoo, identity construction, stigma, art, bussiness.

This study aims to examine the meaning of the reality of individual social interest in body art tattooing or tattooing as an identity so that they bind themselves into a social community. Tattoos in Indonesia with the inherent negative stigmatization, have the complexity of debate in the dynamics of their presence in the public sphere. This paper presents one perspective, especially from the point of view of tattoo owners regarding their perceptions of the motives for tattooing that they do. By conducting observations and in-depth interviews in an effort to make a qualitative scientific explanation of the ownership motives of tattoos by community members. By triangulation techniques, the author builds a constructivist framework of perception of tattoos in the community. This study found that a person's main motivation for having a tattoo is preceded by a desire to express artistic or artistic desires. When this accumulation of shared desires takes place, business motives and identity construction become a trigger for the formation of the tattoo community.

\section{INTRODUCTION}

We often see people who use tattoos, both in the neighborhood and in the mass media. The tattoos adorn one or several parts of their body. If viewed from its history, tattoos cannot be used by people carelessly, the purpose and purpose and special meanings of the use of tattoos. Looking at the history of tattoos in Indonesia, realistic tattoos get a negative response. People who use bad tattoos, often make trouble, and are often identified with criminals. This reality is formed and can be resolved in the 1980s occurred Petrus events (mysterious shootings) against evil people (Sejarah, 2010).

At present there are many specific communities whose goals are set up that do not meet human needs. In accordance with the objectives and characteristics of the community. Those who are members of one community have the same interest in one thing. In terms of health sociology, research on the meaning of tattoos by community members is very interesting to do. Research can be done by examining the meanings and factors that drive interest in tattoos carried out by community members, as well as how interactions are 
carried out in the community. Associated with qualitative research received by the author Appropriate for this study because the research conducted is related to the evolution of human life, namely the meaning and interaction carried out by humans. The social reality construction perspective that addresses the appropriate study of this. The author uses the perspective of the construction of reality as a guide in expressing the construction of meaning carried out by community members.

In this regard, the author tries to examine the phenomenon of the meaning of tattoos on community members through research and pour them into scientific work in written form with the title Construction Meaning of Tattoos on Members of the Tattoo Community.

Based on the data obtained by the author in the study of texts, articles, and journals in conducting research, the authors found a phenomenon of the reality of the meaning of tattoos on community members. The author sets the focus of the research, namely how the social reality of the meaning of tattoos is done by members of the tattoo community. Realizing the capacity and intensity of science, experience and other factors that can support the perfection of research results, and in order to focus the discussion, the main issues that will be examined by the author, namely a) What is the reality of the meaning of tattoos in the view of members of the tattoo community; b). What factors lay behind their interest in tattoos.

\section{LITERATURE REVIEW}

The author hopes this research is useful to add insight to the author both in terms of theoretical and practical about issues related to the formation of the reality of the social meaning of tattoos. From a scientific point of view, this research is expected to be useful to add scientific insights in the field of sociology, especially in the study of Health Sociology, related to the formation of meaning through social processes and interactions, using perspectives or views expressed by Peter L. Berger and Thomas Luckmann (Kuswarno, 2008) related to construction social reality. In addition, the authors hope this study can be a reference material for further research. 
The practical usefulness from the results of this study is expected to be a reference and input for readers in understanding and viewing the reality of the meaning of tattoo socially. In addition, the authors hope that this study will contribute positively to the tattoo community.

\section{METHOD}

This type of research used by the author in the study of the meaning of tattoos on community members is a qualitative research method. The reason the authors use this method is because qualitative research methods are more suitable for research related to human life that is constantly changing. In addition, Deddy Mulyana said that "qualitative methods are especially feasible to examine attitudes or behaviors in the natural environment rather than in a somewhat artificial environment" (Mulyana, 2004)

In the study the authors use the phenomenological research tradition as a guide in writing this study. The reason the writer uses the phenomenological tradition is because the writer is trying to find an understanding of the meaning of a reality based on the experiences passed by humans. The reality referred to by the author is the meaning of tattoos carried out by community members. The author tries to find an understanding of the meaning of tattoos for community members and how these meanings are produced.

Data collection techniques with documentation or document review carried out by the author to obtain data. This technique is carried out by the author by collecting data from various sources of writing that are relevant to a predetermined theme. The author collects data and information from various written sources that can assist in conducting this study. Bogdan stated "in the most tradition of qualitative research, the personal phrase doctrine is used broadly to refer to any for stated narrative produced by an individual which describes his or her own actions, experience and belief" (Bungin, 2008). The author collects, reads, and reviews data in the form of text and images from various written sources and electronic journals about the tattoo community. 


\section{RESULTS AND DISCUSSION}

\subsection{The Meaning of Tattoos For Members of the Tattoo Community}

Members of the tattoo community are lovers and fans of tattoo art in Indonesia. They have their own meaning related to the actualization of himself in tattoos. Their experiences, their awareness of everything related to tattoos, as well as the social actions that occur between them and their environment, have a role in the construction of the reality of the meaning of tattoos socially according to their own views. Their status as lovers and fans of tattoo art, the majority of whom are tattoo artists in Indonesia, is an intentional act of awareness of the values of tattoos for them. Tattoo values referred to here are interests in the form of feelings of pleasure, pride, and passion for tattoo art.

Members of the tattoo community consist of tattoo artists and participant members. Five members of the tattoo community from sources cited by the author are tattoo artists, while the other three sources are participant members. Both categories of members are from the category of members in the tattoo community.

The meaning of tattoos on community members is interpreted from three aspects, namely from the aspect of art, business aspects, and identity (Tato, 2011). As a tattoo artist, tattoos are interpreted from three aspects, namely art, business, and identity. As for the tattoo participants, the meanings are of two, namely aspects of art and identity. Tattoos from the art aspect are interpreted in the form of hobbies, expressions, creativity, and lifestyle. While from the business aspect, tattoos are interpreted as a source of income, or land that works as a tattoo artist and studio owner. Tattoo as an identity is a manifestation of a person or as a symbol to describe someone based on the intent and purpose of the tattoo they have. In addition, in the realm of community and social environment, tattoos also become their identity that shows that they are lovers and fans of tattoos.

Even for tattoo artists or participants in the tattoo community, it is interpreted as a form of expression. Among other things, they interpret the tattoo as a symbol to remember 63 
or remember something. The meaning of tattoos as creativity is related to the various works of tattoos they make. The meaning of tattoos for community members as a lifestyle is a manifestation of their decision to use tattoos. The meaning of tattoos as a source of income can be seen from the marking attached to them, namely their background and experience as a tattoo artist, both a studio artist himself or working as a tattoo artist in someone else's studio. In addition, the identity can be understood through their intentions to express their identity as lovers and fans of tattoos, especially to community members.

Referring to Husserl's phenomenology which focuses on the formation of meaning starting from consciousness, intentionality, to the individual's knowledge of objects, the writer gets a picture of the process of forming meaning (Kuswarno, 2009). The awareness of the tattoo community members can be seen from how they view and value the tattoo. Their intention to enter the world of tattoos is a form of their decision based on their assessment of tattoos.

\subsection{Factors of Interest of Tattoo Community Members towards Tattoos}

The study of motivation, goals, and other concepts and ideas, illustrates for the writer that in a person's behavior and actions there are factors that trigger those behaviors and actions. Related to this study, the authors found that there are factors that encourage members of the tattoo community to interpret tattoos according to their own views, through the construction of the meaning and social reality of the tattoo they do.

Members of the tattoo community construct the meaning of their own tattoos based on the experiences they have experienced as lovers and fans of tattoos, both tattoo artists and tattoo artists and members of the participants. The author gets the picture that their awareness in the form of an interest in tattoo art is motivated by several factors. These factors are related to the concept of Husserl's phenomenology related to his unit of analysis in his transcendental (mental) phenomenology, namely intentionality, norma and noesis, intuition, and intersubjectivity. 
As for the factors that influence an individual's interest in tattoos, the author uses the concept of phenomenology Alfred Schutz who views that the essence of meaning can be reviewed through the perspective of Max Weber's social action.

Based on the content analysis study conducted by the author and referring to the concept of phenomenology of Alfred Schutz, the author gets an overview of the factors that affect the interest of members of the tattoo community, including: internal motivation, external motivation, skills and goals.

The internal motivation referred to here is the arising of love, pleasure, hobbies, and interest from individuals in the art of tattooing itself. While the external motivation that constructs the meaning of tattoos for them is the environment, namely the environment of family, friends, and exposure to information from the mass media. The goal, which is to eliminate the stigma of tattoos inherent in the community. In other words, they want to popularize tattoos and prove that the stigma attached to tattoos in Indonesian society in general depends on certain contexts and viewpoints. The skills possessed in several references contribute to the meaning of tattoos, that involvement in the world of tattoos is an effort to channel their talents in the field of education, namely design education. While other sources found that his skills in making tattoos were obtained by self-taught by learning from friends and other tattoo artists.

Berger and Luckmann explain that the formation of the world and social reality through simultaneous stages, namely externalization, objectivation, and internalization. In this stage, there is a reality that is viewed subjectively, objectively, and symbolically. Society according to Berger and Luckmann can be seen as both a subjective reality and an objective reality.

Members of the tattoo community carry out internal communication activities in the form of exchanging information about matters relating to developments or trends in tattoo art. Among other things, members used to gather to exchange information related to the tools and materials used to tattoo someone's body. As one of the business activities, tattoo studios need to consider the cleanliness of the tools and materials used before tattooing or 
body piercing. Because the sterility of the materials and tools used are very considered in the industry. In addition to discussing matters relating to the tattoo manufacturing service industry, ordinary members gather to discuss what activities will be carried out.

From the description of the reality of the meaning of tattoos and the factors forming the interests of members of the tattoo community, the authors describe the construction of the meaning of tattoos on community members into a diagram that aims to better explain and visualize the description. The author describes the description in a diagram as follows:

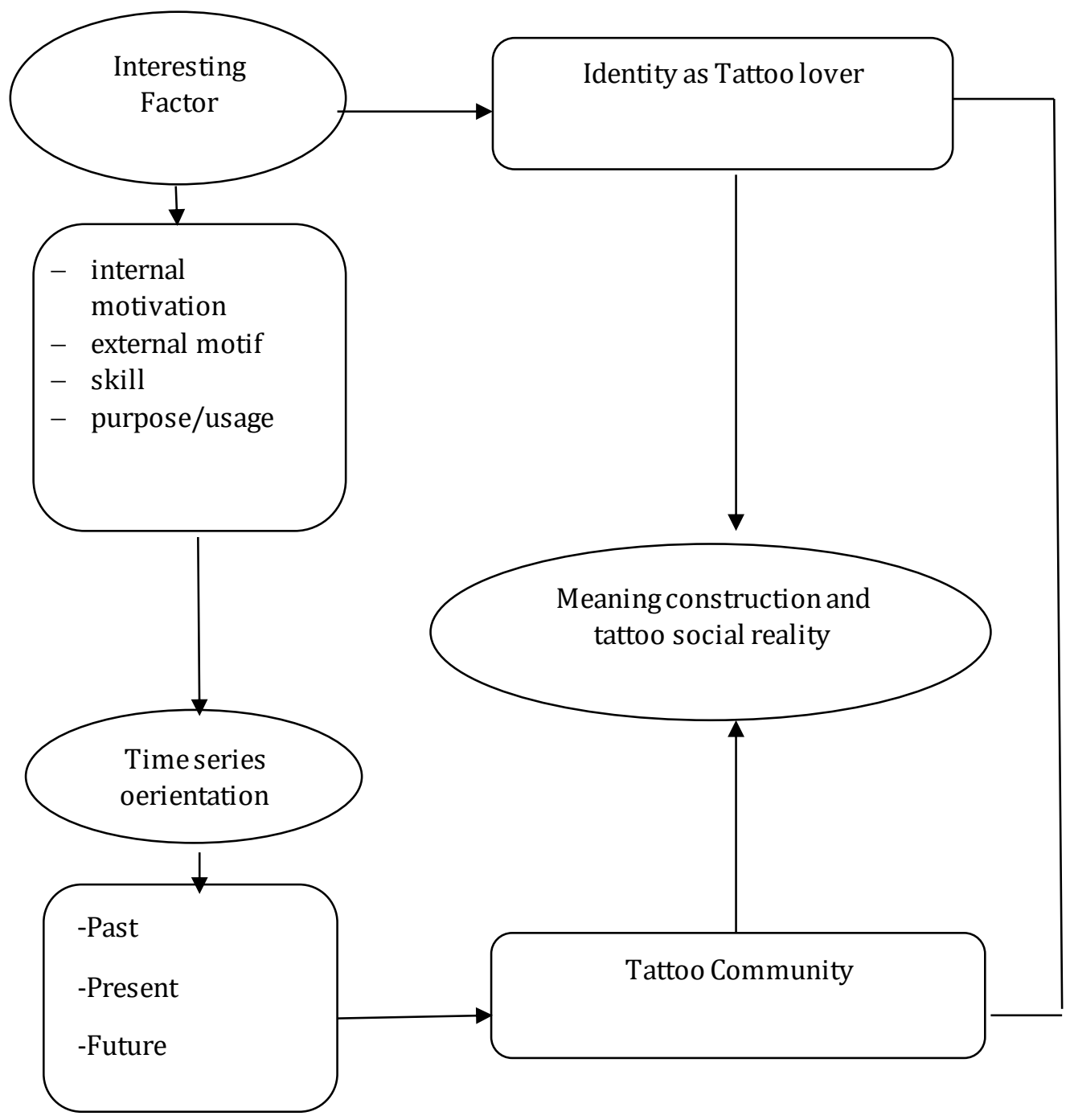


Through the picture above, the author illustrates what and how the process of construction of the meaning of tattoos carried out by members of the tattoo community on members of the tattoo community in Indonesia is produced through construction in the cognitive realm of individuals and the realm of community. In the realm of individuals, the construction of the meaning of tattoos involves internal factors, external factors, skills, and goals. Internal factors in question are feelings like a tattoo and a hobby in using tattoos. Feelings like something is a form of individual awareness in doing intentional. Same with the feeling of love that is owned by members of the community towards the art of tattooing creates intentional use of tattoos, to become a habit or hobby. In addition, the skills acquired by individuals in the field of design as well as self-taught encourage individuals to be interested in tattoo art. Their interest in tattoos is also caused by the influence of the environment. Among these are family members who use tattoos have an indirect effect on individuals to do the same thing. Besides family, the social environment also influences the individual's interest in tattoos.

The first category is the previous orientation, which is the understanding and experience they have related to the negative image attached to the tattoo. Kateori's next time is orientation to the present, meaning they understand the function of the tattoo community as a container for lovers and fans of tattoo art. Future orientation means that they hope to contribute to the promotion of tattoo art. That is, they hope that people do not have to always identify tattoos and tattoo users with negative things.

From the description above, the writer poured a media analysis (content analysis) with the construction of meaning and social reality in tattoo community members into a model of meaning construction. The author uses the concept of Husserl's transcendental phenomenology to analyze the mental formation of meaning in the realm of individuals. The author uses the phenomenology of Alfred Schutz to do an analysis of the factors underlying the interest in tattoos. As for the process of constructing the meaning and reality of tattoos socially, the writer uses the concept of Berger and Luckmann about the construction of reality socially. 


\section{CONCLUSION}

Based on the results of the study and discussion in the previous chapter, the conclusions of this study are:

1. The reality of the meaning of tattoos according to the views of members of the tattoo community as identity, artwork, and business. The meaning of tattoos as an identity shows their identity as lovers and fans of tattoos. The meaning of tattoos as art includes hobbies, expressions, creativity, and lifestyle. While the meaning of tattoos as a business is a source of income.

2. Factors underlying the tattoo community members' interest in tattoos are formed in two spheres, namely the realm of the individual and the realm of the community. In the realm of individuals, their interest in tto is motivated by four factors, namely internal motivation, external motivation, skills, and goals. Whereas in the realm of community is motivated by three factors, namely the previous orientation, present orientation, and future orientation.

3. The meaning of tattoos has shifted from the past until now, ranging from traditional culture, popular culture, counter culture, to consumption and commercialism. In Indonesia, tattooing received a negative response in the 1980s, but currently the use of tattoos is more to the development trend of fashion and lifestyle of a person.

By this study the author would like to submit several suggestions and recommendations, namely:

1. Meanings carried out by individuals of tattoos today are diverse and are motivated by various aspects. The author suggests a comprehensive or comprehensive assessment of the use of tattoos from various aspects based on the underlying factors. 
2. The author recommends that potential tattoo users carefully consider the purpose and motivation of using the tattoo, as well as pay attention to the development of tattoo tattoo socially in the community, because the tattoo is attached to the body of a living well.

\section{ABOUT THE AUTHOR(S)}

The authoris the lecturer from Departement of Sociology, Faculty of Social and Political Sciences, Universitas Bangka Belitung, Indonesia

\section{REFERENCES}

Bungin, B. (2008). Sosiologi Komunikasi: Teori, Paradigma, dan Diskursus Teknologi Komunikasi di Masyarakat. Jakarta: Kencana.

Fisher, A. (1997). Teori-Teori Komunikasi. Bandung: PT Remaja Rosdakarya.

Kuswarno, E. (2008). Etnografi Komunikasi. Bandung: Widya Padjadjaran.

Kuswarno, E. (2009). Fenomenologi. Bandung: Widya Padjadjaran.

Mulyana, D. (2004). Metodologi Penelitian Kualitatif. Bandung: PT Remaja Rosdakarya.

Nonadita. (2010, 9 2). Tato Mentawai, Tato Tertua di Dunia. Retrieved from http://travel.nanadita.com: http://travel.nanadita.com/tato-mentawai-tato-tertuadi-dunia

Sejarah, B. (2010, 11 11). Sejarah-Tato-Mentawai-Tato-Tertua-Di-Dunia. Retrieved from http://blog-sejarah.blogspot.com: http://blogsejarah.blogspot.com/2010/11/sejarah tato-mentawai-tato tertua-di.html

Tato, G. S. (2011, 09 20). Tatto dalam Perspektif Agama Islam. Retrieved from gambr-senitatto.blogspot.com: http://gambar-seni-tatto.blogspot.com/2011/09/tatto-dalamperspektif-agama-islam.html

Thoha, M. (1998). Perilaku Organisasi. Jakarta: PT Rajagrafindo Persada. 